
SUSTAINABILITY.

\begin{abstract}
Since the 1970s, debates on "population growth" and "sustainability" have fluctuated markedly between pessimistic forecasts and optimistic certainties. Nowadays, they have reached a strange, comfortable illusion according to which the demographic future of our planet does not seem to be a problem at all. Nevertheless, median population growth projections by 2100 indicate that an arrest of the increase by the end of the century is rather unlikely. The future prospect is made even more critical by the fact that the increase will occur in what can be called demographic "Growing spots", strongly opposed to just as many "Ageing spots". In these terms, therefore, the future demographic dynamics will certainly pose a challenge to the "population growth-sustainability" combination, for which it will be necessary to develop a new paradigm capable of operating in a "strong transcalar perspective", within a global space that will increasingly acquire characteristics of fluidity and changeability.
\end{abstract}

\title{
Keywords
}

Population growth, Sustainability, Development

\section{Population growth and sustainability}

It is well-known that, in the course of the Anthropocene, the human species has demonstrated a great capacity to transform the planet in order to fulfill its needs through the development of an increasingly complex economic organization and the use of increasingly advanced technologies. During its millennial growth and along its progressive march towards the conquest of ecumenical spaces, humanity has also repeatedly paid firsthand for its mistakes, not always made consciously, encountering tragic failures that have led to the extinction of flourishing civilizations or the destruction of entire ecosystems. The population, however, has also been able to adapt to the variety of terrestrial environments, engaging with them in a constant dialectical relationship in which flexibility, adaptability, and resilience have been for a very long time not only essential prerogatives for survival when confronted by exogenous constraints (famines, epidemics, natural disasters, wars) but also the key in the construction of the world as we know it today (Fernandez-Armesto 2001; Diamond 2011).

The links among development, environment, and population growth have been studied for a long time, but the "population growth-sustainability" combination can hardly find its place even today, always being placed in a marginal and very uncomfortable position in both the 
scientific literature devoted to the growth of world population and that dealing with major problems related to global equilibria. Even if population growth, both in the long and short term, inevitably falls in the debates on major economic, social, and ecological world topics, the complexity of demographic phenomena is rarely discussed as an element of sustainability in itself (Arman and Davidson 2014).

In fact, classic models, developed to represent and connect the different components of sustainability, generally hinge within a triadic system that links the environment with the economic dimension and social, political, and institutional components.

These three-dimensional models work as an integrated system insofar as all the components of the system are interconnected, interdependent, and complementary. Their activation generates a series of actions-reactions in which the individual elements become part of a unique and complex evolutionary process in which sustainability is achieved when all the components are at equilibrium. Within these models, however, population growth is never shown clearly, but appears, in varying degrees, as an active or passive factor belonging to the other components of the system (Adams 2006; Todorov and Marinova 2009; Ciegis et al. 2009).

Nevertheless, population dynamics not only interact with economic development and intervene in modifying the exchanges between social groups and influencing the ecological equilibria, both locally and globally, but often constitute a variable that is completely independent and not always controllable in the system of equilibria of a territory, so much as to undermine the economic growth and development of many countries (Dasgupta 2007).

In fact, the determinants that trigger the people's demographic behaviors are connected, in a correlation which is both positive and negative, to several factors that find their roots in cultural traditions, religious worship, the despair of poverty, or the search of increasingly refined wealth. Some of these behaviors are subject to very slow inertial dynamics, others are influenced by traditions and rituals difficult to mutate, others are sped up by laws or institutional changes, others are launched by technological innovations, and others again are caused by rapid upheavals, generated by contingent events, the rampancy of war, or the devastating power of nature (Livi Bacci 2012).

Each population has its own extraordinarily peculiar demographic dynamics, which are the result of the uniqueness of its own historical, cultural, economic, and geographical situation, so that, even within the classic transitional model, each country is expected to realize its own changes that will be unique and unrepeatable (Chesnais, 1986; Caldwell, 2007; Bongaarts, 2009).

However, the fact that there is a relationship between population growth and increased pressure on resources, accompanied by the degradation of the natural environment, comes as no surprise and has been frequently discussed in different perspectives since very ancient times, such as in some tablets of one Babylonian Epic poem written in 600 B.C., in the Homeric Cypria (776-580 B.C), or in De Anima by Tertullian, a Latin-writing Christian author of the Severan age (Kilmer, A.D. 1972; Hugh G., White E. 2008; Holland 1993). 
From then on, the effects, both negative and positive, that population growth may have for humankind have attracted the interest of philosophers, economists, and scholars throughout all periods of history, from Machiavelli to the Mercantilists, from the Political Arithmetics to the famous Essay on the Principle of Population by Malthus. However, over the centuries, population growth has been the subject of study more often in relation to the consequences that its size could have on political institutions, economic development, and social systems rather than on environmental degradation (Malthus 1798; Overbeek 1974).

From Malthus onwards, the discussion around population growth, related to the future prospects for humanity, became richer and more dynamic, polarizing the historical and philosophical tradition and the studies into the two extreme positions represented by the "Malthusians" and those who opposed the overpopulation theory. The latter have often been labeled "Cornucopians" because of their faith in the powerful reproductive forces of nature, as was the case for political economist Henry George in his book Progress in Poverty written in 1879 (George 1920; O.Neill 2001; Neurath 1994).

Concerns about population growth and the impact this could have on the environment continued to be considered from time to time, with supporters on both sides, but started to flare up in the late 1960s and early 1970s. In 1962, in fact, biologist and nature writer Rachel Carson published her book Silent Spring, which paved the way for the spread of ecological consciousness and fed what would become the environmental movement. In the same period, the concept of carrying capacity began to be employed in applied ecology to analyze the interactions between human activities and the environment, with the widely cited IPAT formulation (Ehrlich \& Holdren 1971; Seidl \& Tisdell 1999; Carson 2002; Robertson 2012).

During these years, the debate about population growth, resource limits, and environmental degradation took on many different shapes and sizes, but those items were not always connected (Durand 1967; Sauvy 1972). However, it is precisely in these years of debate and ferment, both in scientific literature and in the most popular books, that the rise of the total number of living humans entered into the debate over the Earth's future and alerted people about the importance of environmental issues, creating the linkage between population growth and the concept of sustainability, albeit unexpressed.

\section{The roots of the linkage between population growth and sustainability}

The current size of the world population is the result of the fracture, thanks to human ingenuity, of the natural population-resources relationship on which the ancient demographic system was based. The modern transitional process that began in Europe in the second half of the 1700s, coinciding with the economic and technological changes of the Industrial Revolution, triggered a population growth unprecedented in human history. This growth became more intense, albeit with variations in the causative modalities in different geographical areas, after the Second World War, with declining mortality in developing countries. In these areas, however, the slow decline in birth rates has generated extremely 
rapid transitional scenarios, characterized by changes in the population structures, large imbalances in the distribution of resources, increasingly rapid, unpredictable, and majestic migration flows, and above all, it has opened the way for a gradual redefinition of the geopolitical equilibria of population in different regions of the globe (Livi Bacci 2012).

Clearly, the last fifty years have been an exceptional period in the history of world population, both for the great growth that affected it and for the great transformations that occurred in the social, scientific, economic, and technological fields.

In fact, population growth in the five-year period 1965-1970, in which the annual rate of population change rose to $2.06 \%$ globally and $2.56 \%$ in the least developed countries, the highest level ever registered, are described by Paul Ehrlich in his 1968 book Population $B o m b$, foreseeing a future of famine and death for hundreds of millions of people in just a few years (UN 2015c). Ehrlich pointed out the increase in the rate of human beings from 1850 inward and, emphasizing the simple biological challenges posed by rising population, he was sure that no changes in behavior or technology could have saved humanity unless people can achieve control over the size of the human population.

In those years, the concept of "sustainability" had yet to reach its full theoretical maturity. However, in Ehrlich's volume, the idea of necessary equilibrium among population, economic development, and conservation of the natural environment is already clear, though not explicitly expressed with the term "sustainability", which would only be used a few years later. Above all, the prospect of inter-generational and intra-generational responsibility in the management of the planet's resources, which would become one of the fundamental bases of the concept of "sustainable development", is very well outlined from the first pages of the book (Ehrlich 1968).

The alarmism triggered by Ehrlich built on the background of the studies carried out in 1948 by Vogt and Osborn. In 1948, William Vogt published his book Road to Survival and, in the same year, Our Plundered Planet by Fairfield Osborn was also published. These authors, surprisingly, although focusing on an urgent concern for the fact that "the tide of the earth's population is rising", already propose many instances that would form the theoretical basis of the environmental movement that arose twenty years later and begin to feed a rich blooming of studies in which, for the first time, concerns about the consequences that population growth could have on the environment also emerge (Vogt 2013; Osborn 1948; Desrochers \& Hoffbauer, 2009).

In 1972, the report "Limits to Growth" by the Club of Rome, in which population growth effectively becomes one of the protagonists of global ecological balance, was issued. The conclusions clearly explain that it is necessary to intervene to modify the world demographic trends in order to establish a condition of ecological and economic stability that is sustainable in the far future (Meadows et al. 1972).

The study by Meadows was followed, at the beginning of 1981, by the volume Building a Sustainable Society, written by the founder of the World Watch Institute, Lester R. Brown, in which the author gives a warning to the readers about what could happen to their 
contemporaries if the population did not decrease its growth pace. Brown offers a number of helpful tips on how to avoid the imminent and, according to him, almost inevitable catastrophe through a process of change in social values, the use of alternative energy sources, and the development of economic processes of an ecological type. But, above all, the author shows that it is indispensable to curb population growth through family planning and birth control (Brown 1981).

In the 1987 report "Our Common Future", the demographic topic is addressed directly in the fourth chapter as a "common challenge" and recognized as a key factor in the process of consumption and gradual deterioration of environmental resources. However, the Brundtland Commission, although clearly reaffirming the urgency of the need to curb population growth and recognizing that there is a conflict between population growth and development, seems to be less concerned with the size of global population than it is with the progressively worsening quality of people's lives, especially in countries with high demographic pressure, and the inability of many governments to provide education, health care, and food security for their people, let alone their ability to improve living standards (Brundtland 1987).

This standpoint would appear to express more confidence in the ability of the planet to cope with population growth, thanks to increased food production and technological innovations, compared to the possibility of the population to change their reproductive potential in the short term. In fact, between 1960 and 1985, thanks to the green revolution, world production of food resources in developing countries experienced considerable increases, doubling and in some cases tripling crops, thanks to the spread of new techniques developed due to technology and genetics (Patel 2013).

These achievements pave the way for a progressive confidence in the ability of man to stop, thanks to his ingenuity and technological breakthroughs, the vicious circle of the "Malthusian cage"; that is, the inescapable relationship between the availability of natural resources and population growth, as Malthus (1798) noted. In the mid-80s, population growth, which had seemed unstoppable, unsustainable, and threatening to catastrophists, began to appear as less frightening and even went so far as to be interpreted positively for mankind.

In fact, the reflections of E. Boserup, in his 1981 essay Population and Technology, while recognizing the need to maintain a proper balance in the relationship between natural resources and the size of population, saw population growth as a favorable opportunity for humanity insofar as it would allow more people to share the burden of collective investments, spurring productivity and reducing poverty (Boserup 1981).

Since 1970, the person that has made the biggest effort to refute the alarmist predictions by Neo-Malthusian catastrophists is J. Simon. In his 1990 essay Population Matters, Simon argues that population and productivity growth are not independent forces competing with each other, and that, on balance, humans produce much more than they destroy. Moreover, more people are more likely to obtain technological advances, develop inventions, and devise, adapt, and disseminate new knowledge that can increase productivity and improve the quality of people's lives. These viewpoints are highly contradictory and sometimes difficult to share 
in a world that, in the five-year period 1975-80, was facing, in less developed regions, an infant mortality rate still above 136 per thousand and a life expectancy at birth that reached only 45 years (Simon 1981; UN 2013).

Nonetheless, Simon's ideas reached great consensus and, in time, were also supported by the decline, albeit slow, of the birth rate in many countries worldwide thanks to the launch of numerous government programs for the implementation of primary education, contraception, and female empowerment, as a result of the reflections and stimuli by his Neo-Malthusian opponents. In fact, the fertility decline that began with a gradual spread of reproduction management through family planning fits within a very articulate and complex system of changes that started in the 1970s and allowed for humanity to escape the Malthusian trap of demographic crisis. Earth, in fact, has experienced in the last fifty years, together with the population growth, a considerable increase in food production per capita, a substantial decrease in resource prices, a widespread process of globalization, and a general decrease in the percentage of people below the threshold of poverty in developing countries. The increase in school enrollment has been equally rapid in every part of the world as well as a general improvement in life quality due to the epidemiological transition with a reduction in infant mortality and an increase in life expectancy at birth (Lam 2011).

\section{The Contemporary Illusion}

The world population in 2015 amounted to approximately 7.3 billion people and is projected to rise by about a billion within the next twenty years, reaching 8.5 billion in 2030 , 9.7 billion in 2050 , and 11.2 billion in 2100 . Although it is certain that the extraordinary growth that occurred between 1960 and 1999, when the world population doubled in size growing from 3 to 6 billion people in nearly forty years, is unlikely to repeat in the future, the median projections of global population growth by 2100 indicate that an arrest in the increase is improbable by the end of the century, even if the breadth of the range of variability in the estimates is significant. In fact, even if Asian and Latin American forecasts for 2045-50 already indicate a convergence towards growth rates just over $0.5 \%$ per year, and with negative forecasts for the end of the century, in Africa and some geographical areas in Oceania, growth rates show a considerably slower decreasing trend. In particular, for the African continent, average forecasts to 2045-50 still indicate growth values around $2 \%$ per year and $1.2 \%$ in 2095-2100 (UN 2015b; UN 2013).

The contraction in population growth at a global level has been primarily determined by the gradual decline in fertility rates that began in the 1960s, with particular dynamism especially in Asia and Latin America. In these regions, total fertility rates were 5.82 and 5.89 respectively in the five-year period 1950-1955, but by the end of the 1990s they had almost halved, and values continue to fall so much so that today they are close to the replacement level. In Sub-Saharan Africa, the decline in fertility rates, however, has not been as quick: fertility remained almost unchanged during the fifties and sixties, decreasing from 6.75 
children per woman in the five-year period 1970-75 to 5.4 children per woman in the period 2005-2010, and to values equal to 5.1 children per woman in the period 2010-2015, showing much slower reduction forecasts than in other continental areas (UN 2015d).

These future changes in world population, nowadays documented by long-term forecasts that lead to a stationary state, with a fixed structure and low mobility, appear today as being essentially an evolutionary process to be managed in its different phases. This gives rise to what can be defined as the "contemporary illusion". It seems, in fact, that a strange, yet comforting, certainty is now common, according to which the demographic future of our planet can contemplate simple solutions for what, after all, does not seem to be a problem at all. This is the belief, essentially reassuring, that not only the demographic behaviors now in place are likely to continue with ever-greater certainty, converging towards uniform models, but, above all, that also the macroscopic imbalances among geographical regions and ethnic, social, or religious groups, in the vital events related to reproduction, survival, and mobility of individuals, characteristic of the last fifty years and still strongly present, are likely to decrease and vanish in a short time (Livi Bacci 2014).

Furthermore, having averted the catastrophic predictions by Ehrlich has fed, from the 2000s onwards, a progressive indifference of public opinion and, increasingly, also of the scientific press, regarding issues related to the relationships between population growth and demographic sustainability of the planet. Certainly, the long debates between the pessimistic "Neomalthusians" and the optimistic "Cornucopians", which have taken up and amplified, sometimes with excessive alarmist emphasis, the long historical-philosophical tradition about the relationship between the population and the environment have contributed to overloading this subject in a somehow aggressive and contradictory way so much as to exhaust the related interest, indeed fueling a certain detachment with regard to issues related, in some ways, to the problem of overpopulation, and at time giving rise to voices of denial concerning the population growth problem (Bartlett 1994; Catton 1996).

Today, even if the relationship between population growth and increased pressure on natural resources, the loss of biodiversity, and the changing balance in the environmental dynamics at the global level is clearly recognized, it is rather odd that the demographic dimension does not represent at least one of the key priorities in the discourse on sustainability (Ryerson 2010; Das Gupta, Bongaarts \& Cleland 2011). As Grossman (2012) noted, only a small part of the contemporary literature that deals with sustainability focuses on human population and the effects of the growth rate on the environment and global sustainability, except for some theoretical analyses or with an economic approach (Nerlowe 1991; Goodland, Daly \& Serafy 1992; Cohen 1995; Kelley \& Schmidt 1995; Chapman 1999; Marsiglio 2011; Bretschger 2013).

The decreased attention of the scientific debate on the possible consequences of population growth on the Earth's ecological equilibrium has led to progressive indifference, or better, to an attitude of extreme caution by political authorities and institutions in dealing with the issue of demographic size and its short-term consequences for global dynamics. On the other hand, 
more and more attention is paid by governments and leaders to the creation of partnerships and international agreements to reduce greenhouse gas emissions or for the development of global campaigns to achieve goals towards sustainability and development. In this way, many occasions that, coated with the authority of officialdom, could have emphasized the importance of population growth within the global ecological balance and become, therefore, opportunities to include the population within the definition of sustainability, have been irretrievably lost, perhaps for fear of reviving alarmist concerns of a new "Population Bomb".

Similar to the past Millennium Development Goals, even the newest Sustainable Development Goals, in fact, do not contain a specific and explicit Target committed to the growth of the world population. In the new Targets for 2030, there are only a few references that we can define as "strategic" for the management of the dynamics of the world population after 2015 within the ecological context. The most important lies within the Global-Goal5 "Achieve gender equality and to empower women and girls", dedicated to the implementation of gender equality: it is Target 5.6 where we find a clear reference to the need to ensure universal access to sexual and reproductive health in accordance with the principles given in the Programme of Action of the International Conference on Population and Development, the Beijing Platform for Action and the subsequent proposed revisions to these documents. Although the indication toward direct intervention in the context of controlling, or simply monitoring, population growth is not explicitly expressed and therefore not very clear to those who are not very familiar with the matter, the reference to these documents is very important.

Within the Programme for Action, in fact, not only is the close connection among the world's population, development, and ecological and environmental issues recognized, thus connecting the theme of world population growth to that of "sustainability" in the full sense, but, especially in chapters II, III, VI, IX and X, all the critical issues that will characterize the future demographic trends are highlighted, with special attention to the new spatial and structural distribution of the world population (UN WOMEN, 1995; UN, 2015b; UNFPA, 2014).

As well, in the text of the 29 articles of the Paris Agreement, signed on 22 April at the United Nations building by 175 Nations, there are no matches for the word "population" nor for "Family planning". In fact, the document, although recognizing the actual and evergrowing necessity to give a response to the urgent threat of climate change by holding the increase in the global average temperature - well below $2{ }^{\circ} \mathrm{C}$ and no more than $1.5^{\circ} \mathrm{C}$ - and asserting the fundamental priority of safeguarding food security and ending hunger, does not mention the connection between these phenomena and population growth. The document calls on the Nations of the World to take action promoting, respecting, and enforcing obligations concerning human rights, thus improving the right to health of indigenous peoples, local communities, migrants, children, persons with disabilities, and people in vulnerable situations. The Agreement stresses both the importance of the right to development, as well as gender equality, empowerment of women, and intergenerational equity, and the importance of low greenhouse gas emissions, as well as conservation and enhancement of sinks and 
reservoirs of greenhouse gases, in order to ensure the integrity of all ecosystems and protecting biodiversity. The importance of this agreement is vital for the future of humanity and the world's ecological balance and, in these latest recommendations, the virtuous connection with key factors driving the main demographic dynamics can be identified between the lines, but only with the help of the experts' knowledge. However, the international visibility enjoyed by the Paris Agreement could have been a great opportunity to feed the global consensus and raise public awareness about the link between population growth and GHG emissions (UN FCCC, 2015).

\section{Problems and contradictions}

Nevertheless, this "contemporary illusion" clashes with some problems.

The first problem does not lie in the size of population growth in the next fifty years but rather in the imbalance in the distribution through which this growth will occur in some regions of the Earth, and the consequences that this imbalance could generate.

Even if it is true that the forecasts for 2100 are very encouraging, presenting a scenario of stabilization of the world population to values between 9.6 and 12.3 billion people, it is also true that they constitute very long-term projections with a range of variability and uncertainty that leaves much room for error. In fact, these forecasts are based on assumptions regarding the variation in total fertility rate, the minor changes of which, both positive and negative, are sufficient to change the evolutionary trends of the population at the global level (UN 2004a).

The decrease in fertility foreseen by the long-term scenarios for the stabilization of population in 2100 is reachable with a high probability in many areas of the world. However, the factors that affect the reproductive choices of the people are very difficult to control and it is not always possible to predict how each social and cultural context will react to the pressures that lead to change. In fact, for birth control to become an active and effective factor demographically, it must be a conscious choice of the couple, while, at the same time, it must receive social legitimacy, that is, be culturally acceptable so much so as to enter the domain of socially legitimate choices; and, finally, contraceptives must be actually available. In addition, the beginning of a change in reproductive practices does not require the presence of one or either of the three preconditions, but the presence of all of them at once (Coale 1984).

The drop in the fertility rate, unless there is a remarkable and unlikely decline in the coming decades, will not allow for a curb in population growth in the short term, due to the demographic momentum, especially in some areas of the world. Even if we can consider the scenarios oriented towards the stabilization in the long term around the year 2100 as plausible, it should be noted that the evolutionary dynamics of the population in the medium term, between 2015 and 2050, are very diverse at the geographic level (UN 2013).

The largest increases in population, in fact, will occur in the areas that can be defined as demographic "Growing spots", where the total fertility rates will remain relatively high and the structure of the population will be made up of younger cohorts in reproductive age, as 
opposed to just as many "Declining spots" or "Ageing spots" where population will suffer strong contractions due to low fertility and intensification of the aging phenomenon.

In fact, over half of the population growth between 2015 and 2050 will be registered in the African continent. Africa has the highest annual growth rates estimated at approximately $2.5 \%$ per year in the five-year period 2010-2015, with an increase of about 1.3 billion people between 2015 and 2050 amounting to approximately $54.1 \%$ of the total growth. Asia is destined to be the second biggest protagonist of world population growth over the next 35 years, with an estimated increase of about 900 million people between 2015 and 2050, followed by North America, Latin and the Caribbean America, and Oceania, where the increases will be much lower (Gerland et al. 2014).

In particular, the largest increases will be recorded in 48 "Growing spots", which are nations, among which 27 are in Africa, where, in spite of an expected decline in the growth rate, population is expected to double in size from the current 954 million to 1.9 billion in 2050, to reach 3.2 billion in 2100. Some of these countries, including Angola, Burundi, the Democratic Republic of Congo, Malawi, Mali, Niger, Somalia, Uganda, Tanzania, and Zambia will reach five times their population by 2100 . Nigeria, for example, with a population of 182 million inhabitants in 2015, will more than double its demographic weight as early as 2050, reaching an estimated population of 398 million inhabitants and becoming the third most populous nation in the world after India and China, well above the United States of America. In 2100, forecasts see the ever-growing population of Nigeria, exceeding 752 million inhabitants, with a fertility rate of 2.27 children per woman and a growth rate of $0.87 \%$ according to the medium variant.

By contrast, Europe will have the principal "Declining spots", which are areas or nations of the world where, between 2015 and 2050, population will mark a progressive decrease in percentage, equal to or greater than $15 \%$. In particular, this will see the involvement of countries such as: Bosnia-Herzegovina, Bulgaria, Croatia, Hungary, Latvia, Lithuania, Republic of Moldova, Romania, Serbia, and Ukraine, but also non-European countries like Japan. In 2100, Italy, Germany, Poland, Portugal, Spain, Russia, Montenegro, Serbia, Slovenia, and Slovakia in Europe, and Singapore and Sri Lanka in Asia will mark substantial decreases in total population. Throughout Europe, in fact, the fertility rates have been below the replacement rate for several decades and, because of the population structure now heavily aged, not even the predictions of a slight recovery in the TFT estimated for the period 20452050 from 1.6 to 1.8 children per woman or the incremented incoming migration flows seem to be able to limit the population decline (UN 2015b).

The concentration of population growth in the poorest countries will certainly make it more and more difficult for governments to eradicate poverty and inequality, fight hunger and malnutrition, and guarantee education to new generations and basic services for health and hygiene. At the same time, the decline in population in other areas of the world combined with the progressive, and sometimes rapid, increase in the average age will inevitably trigger 
a series of changes in the economic and productive systems, decreasing the labor force and, at the same time, increasing the demand for health and pension services.

The growth of the world's population in the next fifty years will not only determine the uneven growth at the level of regional macro-areas, but also major changes in the geographical distribution of settlements, with an increase in the process of urbanization of the population and a rapid expansion of the coastal urban areas, as well as witnessing the intensification of migration both locally and over long distances. In "Growing spots", the size of the population will often double in two or three decades. As a result, many communities will not be able, in the near future, to cope with the population growth, despite the decline in fertility rates, due to the high number of young women at a childbearing age. This will inevitably generate an increase in slums, overcrowded schools, health systems crises, unemployment, low wages, social and political instability, and unrest and violence.

In contrast, in the most advanced developed countries, the phenomenon of aging will manifest with greater intensity and speed and the population will experience a gradual decline from 2050 onwards. In "Ageing spots", people over sixty years of age will exceed 32\% in 2050, challenging the sustainability of pension systems, public health care, and households (Hugo 2011; Buhaug and Urdal 2013; Bongaarts 2015).

The second problem lies in the relationship between population growth and environmental balance, which will worsen in the areas where the population pressure will be higher over the next fifty years.

As Condorcet (1795) first noted, anticipating by almost two centuries the theories on environmental sustainability, both the size of the population and the choices that man makes in relating with the environment and, therefore, the ways in which he uses resources, determine change in the ecosystem and its capacity to react to degradation and support population. The impact that population has on the environment depends both on its total size and the per capita consumption of resources, as well as the per capita production of waste. Even if Earth's carrying capacity declines as the environment deteriorates, globalization conversely tends towards the homogenization of the demand for consumer goods, infrastructure, and energy, projecting an ever-higher increase of the per capita environmental impact, precisely in the areas with high population growth, and especially in developing countries where environmental problems cannot always be a priority in the policy agenda (The Royal Society 2012).

Before the end of the century, to the more than 7 billion people now living on Earth, between 3 and 4 billion individuals will be added. Several estimates have been made, since the seventeenth century, about Earth's carrying capacity, that is, the number of people that our planet could feed, and, despite the ample variability of the scenarios proposed, everyone agrees that the growth forecasts for 2100 and beyond will be well within the capacity of our production system (UN 2004b; Franck et al. 2011). 
However, the human pressure on the Earth's system has reached a level that would already put in serious jeopardy the ability of the planet to maintain optimal conditions for life within the boundaries of safe operating space for humanity. And it is in fact recognized that, because of the cumulative effects of human activities, we have now passed at least three tipping points exceeding the sustainable limits of the resilience of Earth's biosphere, through rising the global mean temperature, altering the rate of biodiversity loss, and interfering with the nitrogen cycle (Rockström et al. 2009).

The objective adopted by the Paris agreement is to limit climate change well below $2{ }^{\circ} \mathrm{C}$, with rapid peaking of $\mathrm{CO} 2$ in 2040 at current emission rates, and balance emissions and absorption in the second half of the twenty-first century. Beyond $2{ }^{\circ} \mathrm{C}$, experts predict serious consequences for the Earth's climate and ecological system (IPCC, 2014; UN FCCC, 2015).

However, population growth in the next fifty years will concentrate in developing countries thereby generating an increase in both the demand for energy from these regions and GHG emissions. This will be the "paradoxical" consequence of the improvement of living standards and wealth for billions of poor people today, which would dramatically increase what are already dangerous levels of environmental contamination and wastage worldwide, and deplete natural resources already at critical levels (Barnosky, Ehrlich, \& Hadly, 2016).

At the same time, by 2050, as the human population grows, there will be a greater need of land to grow food, which will lead to the destruction of new forest areas or grasslands and, furthermore, as a result of a dietary system which is increasingly animal-based, it is projected that crop and livestock production will increase by $48 \%$ and $80 \%$ respectively, leading to a growth of non-CO2 GHG emissions (Springer \& Duchin, 2014; Bennetzen, Smith, \& Porter, 2015; Gielen, Boshell, \& Saygin 2016).

In the coming decades, the almost certain increase in average temperatures will lead to the expansion of dry-land areas, and this phenomenon, combined with population growth, will lead to an increase in the demand of drinking water from inhabitants all over the world, but especially in arid and semi-arid regions in every continent, for agriculture, livestock breeding, and industrial and energy production. Ground water extraction will become faster than fossil aquifers can recharge and there will be an increase in the number of people living in conditions of water scarcity, with tremendous consequences for a decrease in agricultural productivity (Sherbinin, Carr, Cassels, \& Jiang, 2007; Schade \& Pimentel, 2010).

What seems to be the future for the world's population is only the dawn of a day of great changes that, although certainly leading to a dimensional stability of the population, will require a profound redefinition of the geopolitical balance, economic dynamics, and social relations. These changes are inevitable and can hide great uncertainties and difficulties in adapting along the way, also, and in particular, in ecological and environmental terms.

\section{Towards transcalar sustainability}


In these terms, therefore, the future demographic dynamics will certainly be a challenge to sustainability but, above all, it will be the new structural and spatial distributions of the world population to call into question the need to develop a change in perspective in the perception and action in regard to the "population growth-sustainability" combination. Thus, it is no longer a matter of thinking about a "classic" concept of sustainability, based on the principles of economy, efficiency, and equality - inter-generational and intra-generational - but of taking a step forward and developing a completely new paradigm that allows for the redesign of the "population growth-sustainability" relationship at a holistic level (Pereira 2012).

In the future, in fact, the "global-local" perspective is also no longer sufficient but it will be necessary to take into account the different geographical scales in which sustainability will need to express, putting them in a mutual relationship with each other, as it will be inevitable to consider the "osmotic" tensions that will generate among all the system components at an environmental, social, and economic level, triggering migration flows, conflicts, and exchanges in a geographical space that will increasingly acquire characteristics of fluidity and changeability.

The new paradigm in which the "population growth-sustainability" relationship will be framed will have to operate in a "strong transcalar perspective", that is, it will have to be capable of using conceptual and empirical-analytic tools able to jointly consider different geographical scales and analyze the relations among them, so as to be able to foresee, interpret, and manage a system of dynamic equilibria in time, but above all in space (Bonavero 2005).

All of this makes it such that the complexity of the interactions between demographic and environmental changes can be regarded as an "unstructured problem", that is a complex, multidimensional, ambiguous, and unstable problem that can not be deconstructed into a series of well-defined steps, separated from each other and regulated by precise cause-effect relationships. Moreover, complex problems, not having precise limits or boundaries within which they can be confined, do not lead to a unique solution and cannot even be solved definitively. They have to be continuously managed and adapted to changing environmental situations and spatial, economic, social, and cultural dimensions.

Since it is an unstructured and complex problem, the "population growth-sustainability" relationship cannot be handled with traditional approaches to problem-solving or simply analyzed by applying new information or tools, and not even through the addition of more variables to existing decision-making schemes or mathematical models used for other disciplines. The logic of optimal solutions, in the approach to the complexity of the "population growth-sustainability" relationship, must then be enriched with alternative criteria, such as intuition, consensus level, the acceptance of a particular set of values, and, above all, innovative perspectives that also take into account trans-cultural and emic aspects that reflect the identity of the people who are involved in these processes, especially protecting the most vulnerable subjects and making them participant actors who are involved and aware (Klein 2004; Singer 2011). 
The current momentum of the global human population precludes any "quick fixes" in addressing the demographic imbalances that will begin to appear at the turn of the half of this century and will see the opposition of "Growing spots" and "Ageing spots". In addition to this, there is also the fact that, regardless of an advocated, yet perhaps utopian, downward trend in per capita consumption, population growth in the next fifty years will inevitably lead to an increase in the impact on the environment due to the addition of "pure" growth in the number of global inhabitants to the process of globalization and homogenization of consumption patterns (Bradshaw and Brook 2014).

To prevent the delicate ecological balances from being irreparably damaged and the changes from being catastrophic, and in order to redirect global society toward a more sustainable future, it will be necessary, therefore, to act on multiple levels. Because science and technology cannot act alone in facing and solving environmental problems, it will be necessary to transform societal and economic values and shift away from the view that holds individuals as isolated actors in a competitive world, to one where human beings know themselves to be an integral part of a unique and interconnected biosphere. This not only moves the importance of the "population growth-sustainability" combination to the top of the political agenda and to the core of personal and social belief systems, but also calls for the need to revitalize the debate and scientific research over the effects of human population growth and environmental consumption trajectories.

Revealing which critical scenarios of population imbalance, due to population growth, could materialize in the next fifty years can only be positive if it overcomes sterile alarmism, yet without ignoring the importance of improving and promoting the key factors which drive main demographic changes, such as family planning, empowerment of women, education, and health improvement (Ehrlich, Kareiva, \& Daily, 2012; Mc Alpine 2015).

In fact, the real litmus test of true sustainability after 2015 will be the system's ability to support the population increase not only in its global quantitative dimension but also, and especially, in the complexity of the geographic-spatial relationships that dimensional differences will generate. The problem that society will have to face, in fact, is not the absence of economic or technical solutions, but rather the need to build a broad global consensus on a vision and a strategy to develop policies and approaches that allow for shifting from theories to sustainable practices, not at a global or local level but at a transcalar level, placing demographic size at the center of the triadic system of sustainability.

Since the seventies, it has been clearly recognized that the environmental impact of human activity is attributable to the rate of economic growth, the rate of technological progress, and the rate of population growth (Ehrlich \& Holdren 1971). Many reports and official declarations, diffused worldwide, have recognized and emphasized the need to promote population-related policies at the core of sustainable development. Nevertheless, due to the "contemporary illusion" about the positive management of the problems of growth and distribution of the world population, these calls have not received the right attention in the planning of Sustainable Development Goals and in the international Agenda for development 
and sustainability. This also means that interrelations between population, resources, and environment should be fully included into the sustainable development discussion, recognizing that efforts to promote sustainable development that do not take into account population dynamics, in time and in space, will continue to fail (UNFPA 2012).

The main challenge is to ensure that these principles are properly disseminated and become a well-known and shared heritage. Only in this way will the human-centered and rights-based policies, including access to sexual and reproductive health care, education beyond the primary level and with a focus on girls, the empowerment of women, and family planning become key-factors for sustainable development.

There is a strong need for a revision of the concept of "sustainability", one that includes, finally and definitively, the clear and unequivocal term "population growth" as an independent variable, transforming the three pillars of sustainable development - "Economic development-Social development-Environmental protection"- into a polynomial, as suggested by the Luxembourg Declaration signed in Vienna in 2011, because "[ ... consideration of the changing numbers, characteristics and distributions of human beings on the planet must be at the core of any serious analysis of challenges and opportunities for sustainable development" (IIASA 2011).

\section{Reference list}

Adams, W.M., 2006. The Future of Sustainability: Re-thinking Environment and Development in the Twenty-first Century, Gland, Switzerland.

Arman, M. \& Davidson, K., 2014. A typology to position population within sustainability discourse. Local Environment, 19(4), pp.433-448.

Barnosky A.D., Ehrlich P. R., Hadly E.A., 2016, Avoiding collapse: Grand challenges for science and society to solve by 2050. Elementa: Science of the Anthropocene, 4, pp.1-8.

Bartlett, A. A. 1994. Reflections on sustainability, population growth, and the environment. Population and Environment, 16(1), 5-35.

Bennetzen, E. H., Smith, P., \& Porter, J. R. 2016. Decoupling of Greenhouse Gas Emissions from Global Agricultural Production: 1970-2050. Global Change Biology, 22, 763-781.

Bonavero, P., 2005. L'approccio transcalare come prospettiva di analisi. Quaderni dell'Istituto di Studi su Popolazione e territorio, 3, pp.3-32.

Bongaarts, J. 2009. Human population growth and the demographic transition. Philosophical Transactions of the Royal Society of London B: Biological Sciences, 364(1532), 29852990.

Bongaarts, J., 2015. Global Fertility and Population Trends. Seminnars in Reproductive 
Medicines, 33(5), pp.5-10.

Boserup, E., 1981. Population and technology, Oxford: Blackwell.

Bradshaw, C.J. a. \& Brook, B.W., 2014. Human population reduction is not a quick fix for environmental problems. Proceedings of the National Academy of Sciences, 2014(11).

Bretschger, L. 2013. Population growth and natural-resource scarcity: Long-run development under seemingly unfavorable conditions. Scandinavian Journal of Economics, 115(3), $722-755$.

Brown, L.R., 1981. Building a sustainable society, Norton

Brundtland, G.H., 1987. Our Common Future, Oxford: Oxford Univer.

Buhaug, H. \& Urdal, H., 2013. An urbanization bomb? Population growth and social disorder in cities. Global Environmental Change, 23(1), pp.1-10.

Caldwell, J. C. 2007. Demographic Transition Theory. Springer Science \& Business Media.

Carson, R. 2002. Silent Spring. Houghton Mifflin Harcourt.

Catton, W. R. J. 1996. The Problem of Denial. Human Ecology Review, 3, 53-62.

Chapman, R., 1999. No room at the inn, or why population problems are not all economic. Population and Environment, 21(1), pp.81-97.

Chesnais, J. 1986. La transition démographique : étapes, formes, implications économiques . Etude de séries temporelles ( 1720-1984) relatives à 67 pays . Présentation d' un Cahier de 1 ' INED. Population, 41(6), 1059-1070.

Ciegis, R., Ramanauskiene, J. \& Martinkus, B., 2009. The Concept of Sustainable Development and its Use for Sustainability Scenarios. Challenges, 2(2), pp.28-37.

Coale, A.J., 1984. The Demographic Transition. The Pakistan Development Review, 23(4), pp.531-552.

Cohen, J. E. 1995. How Many People Can the Earth Support? New York: Norton \& Company

Condorcet, J.A.N, 1795. Esquisse d'un tableau historique des progres de l'esprit humain. Ouvrage posthume de Condorcet: Paris.

Dasgupta, P., 2007. The idea of sustainable development. Sustainability Science, 2(1), pp.511.

Das Gupta, M., Bongaarts, J., \& Cleland, J. 2011. Population, Poverty, and Sustainable Development A Review of the Evidence. Geneva.

Diamond, J., 2011. Collapse, London: Penguin Books.

Durand, J. D. 1967. The Modern Expansion of World Population. Proceedings of the 
American Philosophical Society, 111(3), 136-159.

Desrochers, P., \& Hoffbauer, C. 2009. The Post War Intellectual Roots of the Population Bomb. Fairfield Osborn's " Our Plundered Planet" and William Vogt's " Road to Survival " in Retrospect. The Electronic Journal of Sustainable Development, 1.

Ehrlich, P.R., 1968. The Population Bomb, Cutchogue, N.Y: Buccaneer Books, Inc.

Ehrlich, P. R., \& Holdren, J. P. 1971. Impact of Population Growth. Science, 171(3977), 1212-1217.

Ehrlich, P. R., Kareiva, P. M., \& Daily, G. C. 2012. Securing natural capital and expanding equity to rescale civilization. Nature, 486(7401), 68-73.

Fernandez-Armesto, F., 2001. Civilizations, New York: The Free Press.

Franck, S. et al., 2011. Harvesting the sun: New estimations of the maximum population of planet Earth. Ecological Modelling, 222(12), pp.2019-2026.

Gielen, D., Boshell, F., \& Saygin, D. 2016. Climate and energy challenges for materials science. Nature Materials, 15(2), 117-120.

George, H., 1920. Progress and Poverty. Library of Economics and Liberty. Retrieved May 11, 2016 from: http://www.econlib.org/library/YPDBooks/George/grgPP9.html

Gerland, P. et al., 2014. World population stabilization unlikely this century. Science, 234.A

Grossman, R. 2012. The importance of human population to sustainability. Environment, Development and Sustainability, 14(6), 973-977.

Hayes, A. C., \& Adamo, S. B. 2014. Introduction: Understanding the links between population dynamics and climate change. Population and Environment, 35(3), 225-230.

Holland B.K, 1991, A View of Population Growth Circa A.D. 200. Population and Development Review, Vol. 19, No. 2 (Jun., 1993), pp. 328-329

Hugh G., White E. 2008, Hesiod, The Homeric Hymns, and Homerica. Gutenberg ebook Hesiod, the Homeric Hymns, www.gutenberg.org, Cypria, Fragment \#3.

Hugo, G., 2011. Future demographic change and its interactions with migration and climate change. Global Environmental Change, 21, pp.S21-S33.

Kelley, A. C., \& Schmidt, R. M., 1995. Aggregate Population and Economic Growth Correlations: The Role of the Components of Demographic Change. Demography, 32(4), $543-555$.

Kilmer A.D, 1972. The mesopotamian concept of overpopulation and its solution as reflected in mythology, Orientalia, 41, pp.160-176.

Klein, J.T., 2004. Interdisciplinarity and complexity: An evolving relationship. E:CO 
Emergence: Complexity and Organization, 6(1-2), pp.2-10.

IIASA, 2011. The Laxemburg Declaration on Population and Sustainable development: statement of a Global Expert Panel, Laxemburg.

IPCC, 2014: Climate Change 2014: Synthesis Report. Contribution of Working Groups I, II and III to the Fifth Assessment Report of the Intergovernmental Panel on Climate Change. Geneva.

Lam, D., 2011. How the world survived the population bomb: lessons from 50 years of extraordinary demographic history. Demography, 48(4), pp.1231-62.

Lane, M., 2010. The carrying capacity imperative: Assessing regional carrying capacity methodologies for sustainable land-use planning. Land Use Policy, 27(4), pp.1038-1045.

Livi Bacci, M., 2012. A Concise History of World Population, Oxford: Wiley-Blackwell.

Livi Bacci, M., 2014. Fine della demografia ? L'agenda post-2015 per lo sviluppo sostenibile. Il Mulino, 4, pp.1-8.

Malthus, T.R., 1978, An Essay on the Principle of Population, as it Affects the Future Improvement of Society with Remarks on the Speculations of Mr. Godwin, Mr. Condorcet, and other Writers. London, Printed For J. Johnson, In St. Paul's Church-Yard, Project Gutenberg Ebook Essay

Marsiglio, S., 2011. On the relationship between Population change and sustainable development, Research in Economics 65, pp.353-364

McAlpine, C. A., Seabrook, L. M., Ryan, J. G., Feeney, B. J., Ripple, W. J., Ehrlich, A. H., \& Ehrlich, P. R. 2015. Transformational change: Creating a safe operating space for humanity. Ecology and Society, 20(1).

Meadows, D.H. et al., 1972. The Limits to Growth, New York: Universe Books.

Nerlove, M. 2016. Association Population and the Environment: A Parable of Firewood and Other Tales. Agricultural \& Applied Economics, 73(5), 1334-1347.

Neurath, P., 1994. From Malthus to the Club of Rome and Back: problems of limits to growth, population control and migrations, New York: Sharpe Inc.

O Neill B., 2001. Cassandra/Cornucopian Debate, International Encyclopedia of the Social \& Behavioral Sciences. 2001. pp. 1525-1529.

Osborn, F., 1948. Our Plundered Planet, Little, Brown.

Overbeek, J., 1974. History of population theories, Rotterdam: Rotterdam University Press.

Patel, R., 2013. The Long Green Revolution. Journal of Peasant Studies, 40(1), pp.1-63.

Pereira, T. 2012. The transition to a sustainable society: A new social contract. Environment, 
Development and Sustainability, 14(2), 273-281.

Ryerson, W. N. 2010. Population: The Multiplier of Everything Else. The Post Carbon Reader: Managing the 21 st Century's Sustainability Crises.

Robertson, T. 2012. The Malthusian Moment: Global Population Growth and the Birth of American Environmentalism. Piscataway NJ: Rutgers University Press.

Rockström, J., W. Steffen, K. Noone, et al., 2009. Planetary boundaries:exploring the safe operating space for humanity. Ecology and Society 14(2): 32.

Sauvy, A. 1972. La population du monde et les ressources de la planète un projet de recherches. Population, Fr. Ed., 27(6), 967-977.

Schade, C., \& Pimentel, D. 2010. Population crash: Prospects for famine in the twenty-first century. Environment, Development and Sustainability, 12(2), 245-262.

Sherbinin, A. De, Carr, D., Cassels, S., \& Jiang, L. 2007. Population and Environment. Annual Review of Environment and Resources, 32(1), 345-373. doi:10.1146/annurev.energy.32.041306.100243

Schneider, U. A., Havlìk, P., Schmid, E., Valin, H., Mosnier, A., Obersteiner, M., ... Fritz, S. 2011. Impacts of population growth, economic development, and technical change on global food production and consumption. Agricultural Systems, 104(2), 204-215.

Simon, J.L., 1981. The ultimate resource, Oxford: M. Robertson.

Singer, M., 2011. Anthropology as a Sustainability Science. Anthropology News, 52(4), pp.5-10.

Seidl, I., \& Tisdell, C. a. 1999. Carrying capacity reconsidered: From Malthus' population theory to cultural carrying capacity. Ecological Economics, 31(3), 395-408.

Springer, N. P., \& Duchin, F. 2014. Feeding nine billion people sustainably: conserving land and water through shifting diets and changes in technologies. Environmental Science \& Technology, 48(8), 4444-51.

The Royal Society, 2012. People and the planet, London: The Royal Society.

Todorov, V. \& Marinova, D., 2009. Models of sustainability. 18th World IMACS Congress, ..., (99), p.80.

U.S. Census Bureau, 2015a. Historical Estimates of World Population. Available from: https://www.census.gov/population/international/data/worldpop/table_history.php

UN, 2004. World Population To 2300. New York, 18(3), pp.553-561.

UN, 2004a. World Population To 2300, Part One: Report. New York. New York.

UN, 2004b. World Population To 2300, Part Two: Essays. New York. New York. 
UN, 2013. World Population Prospects The 2012 Revision Volume I : Comprehensive Tables, New York: United Nations

UN, 2015b. World Population Prospects 2015, New York: United Nations.

UN, 2015c. World Population Prospect 2015, The 2015 Revision, File POP/2: Average annual rate of population change by major area, region and country, 1950-2100 (percentage), Available

from: http://esa.un.org/unpd/wpp/Download/Standard/Population.

UN, 2015d. World Population Prospect 2015, The 2015 Revision, File FERT/4: Total Fertility Rate by Major Area, Region and Country, 1950-2100 (children per woman), Available from: http://esa.un.org/unpd/wpp/Download/Standard/Fertility.

UN FCCC. Adoption of the Paris Agreement, Conference of the Parties on its twenty-first $\begin{array}{lllll}\text { session } & 32 & \text { (2015). } & \text { United } & \text { Nations. }\end{array}$ from:http://unfccc.int/resource/docs/2015/cop21/eng/109r01.pdf.

UN WOMEN, 1995. Beijing Declaration and Platform for Action.

UNFPA, 2012. Population matters for sustainable development. Report. New York. Avaliable from: http://www.unfpa.org/publications/population-matters-sustainable-development

UNFPA, 2014. Programme of Action of the International Conference on Population Development. Report. New York.

Vogt, W., 2013. Road to Survival Ed Or. 1948 W. Sloane Associates., Literary Licensing, LLC. 